SBP and DBP compared to celecoxib despite providing superior efficacy as determined by PGART and WOMAC.

\section{SAT0096 GASTROINTESTINAL TOLERABILITY IN PRIMARY CARE PATIENTS TREATED WITH NAPROXEN OR ROFECOXIB FOR OSTEOARTHRITIS (OA): THE ADVANTAGE TRIAL}

${ }^{1} \mathrm{GP}$ Geba, ${ }^{2} \mathrm{JR}$ Lisse, ${ }^{3} \mathrm{M}$ Perlman, ${ }^{1} \mathrm{AB}$ Polis, ${ }^{1} \mathrm{ME}$ Dixon, ${ }^{1} \mathrm{CS}$ Skalky, ${ }^{1} \mathrm{~T}$ Dobbins, ${ }^{4} \mathrm{G}$ Johansson, ${ }^{5} \mathrm{JR}$ Shoemaker, ${ }^{6} \mathrm{~J}$ Schechtman, ${ }^{7} \mathrm{AJ}$ Mollen. ${ }^{1}$ Merck \& Co., Inc., West Point, PA, USA; ${ }^{2}$ University of Texas Medical Branch, Galveston, TX, USA; ${ }^{3}$ Scripps Clinic, La Jolla, CA, USA; ${ }^{4}$ Uppsala University, Sweden; ${ }^{5}$ Ormand Beach, FL, USA; ${ }^{6}$ Sun Valley Arthritis Center, Glendale, AZ, USA; ${ }^{7}$ Southwest Health Institute, Phoenix, AZ, USA

\subsection{6/annrheumdis-2001.471}

Background Chronic treatment with dual cyclo-oxygenase (Cox1/Cox-2) inhibitors is known to increase the risk of serious gastrointestinal (GI) adverse events (AE). Rofecoxib, a selective inhibitor of Cox-2 (coxib) exhibits an efficacy profile comparable to dual Cox-1/Cox-2 inhibitors. In a meta-analysis of several $\mathrm{OA}$ trials and in a large prospective study of RA patients, rofecoxib resulted in a markedly lower incidence of serious GI outcomes (i.e. perforation, ulcer and GI bleeding) versus comparator NSAIDs.

Objectives To assess the GI tolerability of rofecoxib compared to naproxen in the treatment of patients with $\mathrm{OA}$ in the primary care setting.

Methods 5597 patients with OA were treated for 3-months in a randomised, controlled trial conducted in the U. S. and Sweden. Patients with clinically defined OA of the knee, hip, hand or spine previously treated with an NSAID, coxibs, or acetaminophen were randomised to receive either naproxen (500 BID) or rofecoxib (25 mg QD). Patients using low dose aspirin for cardiovascular prophylaxis were allowed to enter the trial. The primary endpoint was GI tolerability as defined by the incidence of discontinuations due to any GI AEs. The secondary endpoint was usage of concomitant GI medication to treat GI symptoms initiated during the study. Efficacy and overall safety and tolerability were assessed at office visits at baseline, 6 and 12 weeks and by telephone at weeks 3 and 9 .

Results The majority of patients were female (71\%). The mean age was $63+11$ years. The racial composition was White (87\%), African American (9\%), and other racial origin (4\%). $12 \%$ used low dose aspirin during the trial. The primary study joints were: knee (50\%), spine (24\%), hand (16\%) and hip $(10 \%)$. In $90 \%$ of patients, joints other than their primary joint were involved by OA. $92 \%$ had OA symptoms for more than one year. For prior OA therapy, $62 \%$ of patients used single therapy with NSAIDs, 7\% used acetaminophen alone, and 30\% used both. The most common cardiovascular and GI secondary diagnoses at study entry were hypertension (45\%) and heartburn $(13 \%)$. Treatment groups were similar in baseline characteristics. The primary hypothesis, that there would be lower incidence of discontinuations due to GI AEs in patients treated with rofecoxib, was confirmed (rofecoxib: 5.9\%; naproxen: $8.1 \%$; $\mathrm{p}=$ $0.005)$. The secondary hypothesis, that rofecoxib patients would require less GI concomitant medication than naproxen patients, also was confirmed (rofecoxib: 9.1\%; naproxen: 11.2\%, $\mathrm{p}=$ 0.014). The incidences of lower extremity oedema (rofecoxib: $3.5 \%$, naproxen: $3.8 \%$ ) and hypertension (rofecoxib: $2.9 \%$, naproxen: $2.5 \%$ ) were similar. Concomitant use of low dose aspirin, did not significantly affect relative rates of discontinuation due to AEs, serious AEs or drug related AEs. No significant difference in OA efficacy was noted between treatments for Patient
Global Assessment of Disease Status [Wk 6: $11.6 \mathrm{~mm}$ and 10.8 $\mathrm{mm}$; Wk 12: $10.4 \mathrm{~mm}$ and $9.6 \mathrm{~mm}$; for rofecoxib and naproxen, respectively), the AUSCAN OA Hand Index or incidence of discontinuation due to lack of efficacy.

Conclusion In patients with OA of the knee, hip, hand or spine, which included patients concomitantly treated with low dose aspirin, rofecoxib $25 \mathrm{mg}$ QD demonstrated superior GI tolerability and resulted in significantly less use of concomitant GI medications while demonstrating similar efficacy compared to naproxen $500 \mathrm{mg}$ BID.

\section{SAT0097 SUCCESS IN OSTEOARTHRITIS (OA) TRIAL: CELECOXIB SIGNIFICANTLY REDUCES THE RISK OF UPPER GASTROINTESTINAL (UGI) HOSPITALIZATIONS COMPARED TO DICLOFENAC AND NAPROXEN IN 13,274 RANDOMISED PATIENTS WITH OA}

${ }^{1} \mathrm{~J}$ Goldstein, ${ }^{2} \mathrm{G}$ Eisen, ${ }^{3} \mathrm{~W}$ Bensen, ${ }^{4} \mathrm{~N}$ Agrawal, ${ }^{5} \mathrm{G}$ Singh, ${ }^{6} \mathrm{~K}$ Pavelka, ${ }^{7} \mathrm{TA}$ Burke, ${ }^{8} \mathrm{JVM}$ Chancellor, ${ }^{8} \mathrm{AD}$ Pettitt, ${ }^{9} \mathrm{AM}$ Wilson, ${ }^{7} \mathrm{~J}$ Fort. ${ }^{1}$ Department of Medicine, University of Illinois at Chicago, Chicago, USA; ${ }^{2}$ Vanderbilt University School of Medicine, Nashville, USA; ${ }^{3}$ St. Jospeh's Hospital and McMaster University, Ontario, Canada; ${ }^{4}$ Division of Gastroenterology, Duke University, Durham, USA; 5 Stanford University, Palo Alto, USA; ${ }^{6}$ Czech Rheumatological Society, Prague, Czech Republic; ${ }^{7}$ Pharmacia Corporation, Peapack, USA; ${ }^{8}$ Global Health Outcomes, Pharmacia, Bucks, UK; ${ }^{9}$ Pfizer Inc., New York, USA

\subsection{6/annrheumdis-2001.472}

Background NSAIDs increase the risk of serious GI hospitalizations, with studies demonstrating $5-7 \mathrm{x}$ increases in risk $(1 \%$ ? $1.5 \%$ NSAID vs $0.1 \%-0.2 \%$ background rates). Additionally, GIrelated hospitalizations impose higher cost on payers.

Objectives To compare the incidence of upper GI (UGI) hospitalizations in OA patients exposed to celecoxib, a COX-2 specific inhibitor, or conventional NSAIDs (diclofenac or naproxen).

Methods SUCCESS-1 in OA was a 12-week, multinational, double-blind, randomised trial in 13,274 patients, designed to reflect standard clinical practice. 6547 patients from Europe and Africa; 2756 from North America; 2889 from Latin America and 1082 from Australasia were enrolled. Patients were treated with celecoxib $(200 \mathrm{mg} / \mathrm{d}[\mathrm{n}=4421]$ or $400 \mathrm{mg} / \mathrm{d}[\mathrm{n}=4429])$ or conventional NSAIDs (naproxen $1000 \mathrm{mg} / \mathrm{d}[\mathrm{n}=914]$ or diclofenac $100 \mathrm{mg} / \mathrm{d}[\mathrm{n}=3510])$. An independent Gastrointestinal Events Committee (GEC) categorised potential clinically significant UGI events in a blinded fashion as UGI ulcer complications (perforations, gastric outlet obstruction, bleeding) or symptomatic UGI ulcerations. UGI hospitalizations are reported as GI body system code events, investigator-determined potential UGI events, and GEC-confirmed ulcers/ulcer complications.

Results

\begin{tabular}{|c|c|c|c|c|c|}
\hline & Treatment & $\begin{array}{l}\text { Hospitalised, } \\
\text { n }\end{array}$ & Rate* & $\begin{array}{l}\operatorname{RR}(95 \% \\
\mathrm{Cl})\end{array}$ & $\begin{array}{l}\mathrm{p} \text { - } \\
\text { value }\end{array}$ \\
\hline \multirow[t]{2}{*}{ All GI Hospitalizations } & Celecoxib & 22 & 1.17 & $\begin{array}{l}0.50 \\
(0.28 \\
0.90)\end{array}$ & 0.022 \\
\hline & NSAIDs & 22 & 2.34 & - & - \\
\hline \multirow[t]{2}{*}{$\begin{array}{l}\text { Investigator UGI Ulcers + } \\
\text { Ulcer Complications }\end{array}$} & Celecoxib & 20 & 1.06 & $\begin{array}{l}0.48 \\
(0.26 \\
0.88)\end{array}$ & 0.018 \\
\hline & NSAIDs & 21 & 2.23 & - & .. \\
\hline
\end{tabular}

